\title{
MỘT SỐ ĐẶC ĐIỂM SINH HỌC SINH SẢN CỦA LOÀI MÓNG TAY SOLEN THACHI COSEL, 2002 Ở ĐÂM THUỶ TRIỀ, KHÁNH HOÀ
}

\author{
Đỗ Hữu Hoàng", Hứa Thái Tuyến \\ Viện Hải duơng hoc-Viện Hàn lâm Khoa học và Công nghệ Việt Nam \\ E-mail: dohuuhoang2002@yahoo.com
}

Ngày nhận bài: 9-9-2015

\begin{abstract}
TÓM TÄT: Bài viết trình bày một số kết quả nghiên cứu đặc điểm sinh học sinh sản của loài móng tay Solen thachi Cosel, 2002 là loài có giá trị kinh tế ở đầm Thủy Triều, góp phần cung cấp co sở khoa học cho việc quản lý khai thác loài móng tay một cách hiệu quả và bền vũng. Mẫu vật được thu hàng tháng trong chu kỳ 1 năm với tổng số mẫu là 822 cá thể. Kết quả phân tích cho thấy móng tay là loài phân tính, không phân biệt đực cái bằng mắt thuờng, tỷ lệ đực cái xấp xỉ 1:1. Tuyến sinh dục phát triển theo bốn giai đoạn. Mùa vu sinh sản kéo dài tù tháng 12 đến tháng 3 năm sau, đỉnh cao vào tháng 12. Súc sinh sản tuyệt đối trung bình của móng tay là $1.048 .893 \pm$ 608.964 trứng/cá thể và sức sinh sản tương đối trung bình là $146.349 \pm 95.666$ trứng/gram khối lương. Kích thuớc thành thuc lần đầu 69,6 mm. Bài viết góp phần cung cấp co sở khoa học cho việc quản lý khai thác loài móng tay một cách hiệu quả và bền vũng.
\end{abstract}

Tù̀ khóa: Móng tay, Solen thachi, sinh học sinh sản.

\section{Mở ĐẦU}

Móng tay Solen thachi Cosel, 2002 thuộc họ Solenidae, lớp hai mảnh vỏ Bivalvia. Chúng là loài ăn lọc, phân bố ở những nơi đáy bùn thuộc vùng triều giữa cho đến dưới triều, đặc biệt là ở các cửa sông [1]. Chúng phân bố ở vùng biển nhiệt đới tây Thái Bình Dương (Nhật Bản, Hàn Quốc, Trung Quốc, Philippines). Theo Hylleberg và Kilburn [2] giống Solen ở Việt Nam có khoảng 16 loài. Ngoài những tài liệu phân loại các nghiên cứu về nhóm loài này rất ít cả ở trong và ngoài nước.

Ở đầm Thủy Triều, Khánh Hòa, loài móng tay Solen thachi được khai thác làm thực phẩm và thức ăn cho tôm sú và tôm hùm. Trong những năm 2003 - 2004 việc khai thác mang tính tự phát, người dân sử dụng các biện pháp khai thác có thể ảnh hưởng đến môi trường và thảm cỏ biển. Tuy nhiên, chưa có biện pháp bảo vệ thích đáng. Ngoài ra, cho đến nay chưa có nghiên cứu sinh học nào trên loài móng tay tại đầm Thuỷ
Triều. Vì vây, nghiên cứu sinh học sinh sản của móng tay là dữ liệu khoa học quan trọng và cần thiết cho việc quy hoạch quản lý và khai thác nguồn lợi của đôi tượng này.

Mục tiêu của nghiên cứu nhằm cung cấp dẫn liệu về đặc điểm sinh học của loài móng tay, Solen thachi, cung cấp cơ sở khoa học cho việc quản lý khai thác và sử dụng nguồn lợi móng tay một cách hiệu quả và bền vững, ngoài ra còn làm cơ sở cho việc sản xuất giống nhân tạo nhằm bảo tồn và phát triển nuôi thương phẩm loài này trong tương lai.

\section{PHƯƠNG PHÁP NGHIÊN CÚU VÀ MÃ̃U VẬT}

Mẫu vật được thu hàng tháng từ 7/2005 đến 6/2006 tại Cam Hải Tây và Cam Thành Bắc (Khánh Hòa) (hình 1). Mẫu được thu ngẫu nhiên, mỗi tháng thu ít nhất 30 mẫu. Tổng sổ là 822 mẫu được cố định tại chỗ bằng formol 5\%, và được phân tích tại phòng thí nghiệm của Viện Hải dương học. 


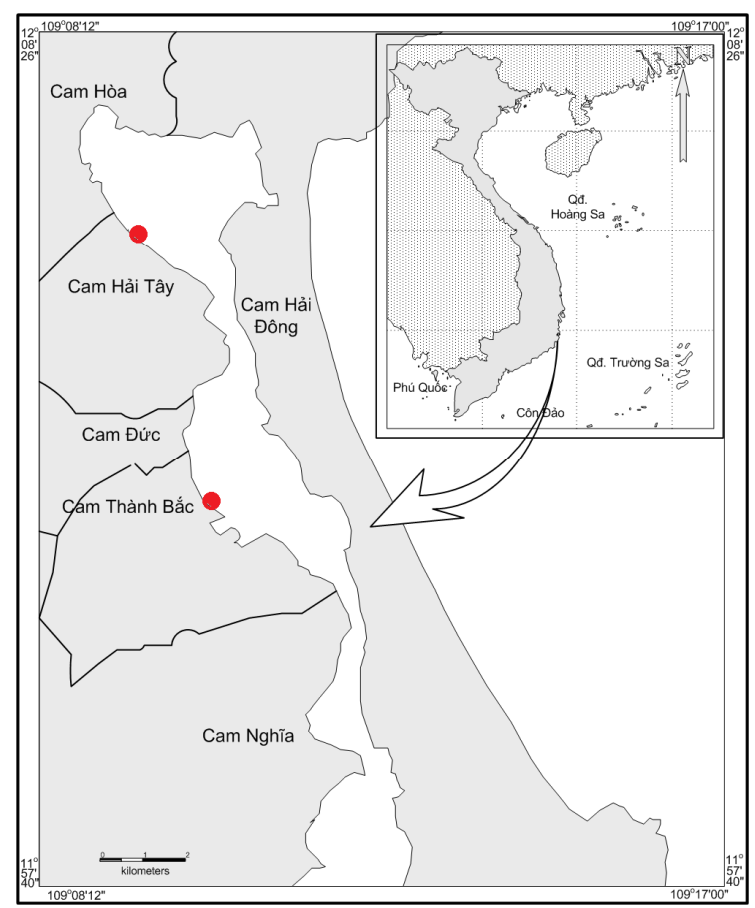

Hình 1. Địa điểm thu mẫu móng tay tại đầm Thủy Triều $(\mathrm{O})$

Kích thước của mỗi cá thể (dài, cao và độ dày) được đo bằng thước kẹp kỹ thuật.

Sau khi đo chiều dài vỏ, sản phẩm sinh dục được giải phẩu và quan sát dưới kính hiển vi ở độ phóng đại $10 \times 10$ hoặc $10 \times 40$ lần. Các chỉ tiêu phân tích bao gồm:

Giới tính và các giai đoạn phát triển tuyến sinh dục theo thang 4 bậc của Baron [3].

Buồng trứng cá thể cái ở giai đoạn III, được cố định trong formol 5\% để xác định sức sinh sản.

Xác định sức sinh sản tuyệt đối, tương đối, tỷ lệ đực cái, mùa vư sinh sản và kích thước thành thục sinh dục lẩn đầu theo phương pháp của King [4].

Sức sinh sản tuyệt đối: Tổng số trứng có thể phân biệt được (giai đoạn III) trong buồng trứng:

Cân toàn bộ buồng trứng $\left(\mathrm{W}_{\mathrm{bt}}\right)$;

Dùng banh lấy 3 mẫu tại 3 phần của buồng trứng (phần 2 đầu và phần giữa) và cân tổng khối lượng của 3 phần $\left(\mathrm{W}_{\mathrm{m}}\right)$;
Tách và toàn bộ số trứng của 3 phần mẫu và đếm tổng số trứng ở giai đoạn III $\left(\mathrm{N}_{\mathrm{m}}\right)$;

Sức sinh sản tuyệt đối $=\mathrm{N}_{\mathrm{m}} \times \mathrm{W}_{\mathrm{bt}} / \mathrm{W}_{\mathrm{m}}$.

Sức sinh sản tương đối: Sức sinh sản tuyệt đối/khối lượng toàn thân (g).

Mùa vụ sinh sản: Đa số cá thể cái có tuyến sinh dục ở giai đoạn thành thục [4].

Kích thước thành thục lần đầu là nhóm kích thước nhỏ nhất ở đó có ít nhất $50 \%$ cá thể cái có tuyến sinh dục thành thục, được tính theo công thức sau: $\operatorname{Ln}[(1-\mathrm{P}) / \mathrm{P}]=\mathrm{aL}+\mathrm{b}$. Trong đó $\mathrm{P}$ là tỷ lệ cá thể cái thành thục ở các nhóm kích thước (L) khác nhau, $\mathrm{a}$ và b là hệ số của hàm bậc 1. Kích thước thành thục bé nhất, $\mathrm{L}_{50}=\mathrm{b} / \mathrm{a}$ [4].

\section{KẾT QUẢ NGHIÊN CÚU VÀ THẢO LUẬN}

\section{Đặc điểm phát triển mô học tuyến sinh dục của móng tay}

Móng tay là loài đơn tính. Phân tích 822 mẫu chưa phát hiện thấy hiện tượng lưỡng tính như một số loài nhuyễn thể khác như báo cáo của Broom [5]. Tuyến sinh dục của móng tay nằm dưới lớp cơ chân, sản phẩm sinh dục rất nhỏ, màu khá giống nhau nên chỉ có thể phân biệt đực cái và các giai đoạn sinh dục bằng cách lấy mẫu và quan sát dưới kính hiển vi ở độ phóng đại 40 - 400 lần [3, 6].

Quan sát các giai đoạn phát triển tuyến sinh dục của móng tay tại đầm Thủy Triều cho thấy, tuyến sinh dục phát triển qua 4 giai đoạn:

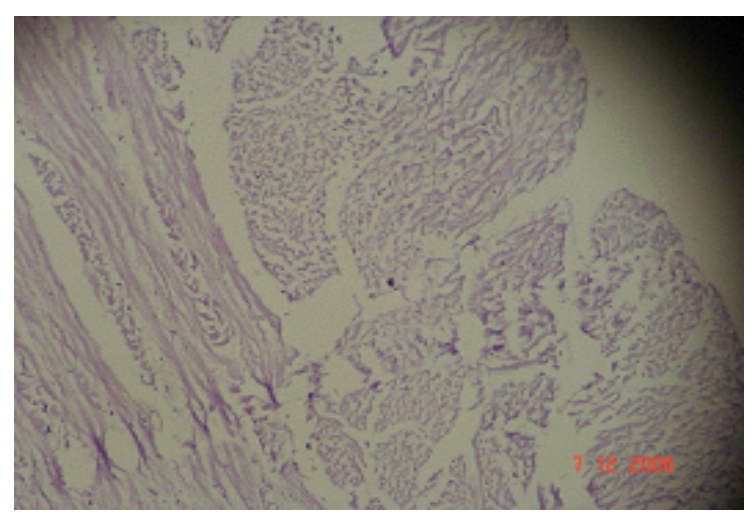

Hình 2. Tuyến sinh dục ở giai đoạn I

(Độ phóng đại 10 × 40) 


\section{Đỗ Hũu Hoàng, Hứa Thái Tuyến}

Giai đoạn I: Tuyến sinh dục nhỏ, khó phân biệt bằng mắt thường, không thể phân biệt được đực cái (hình 2).

Giai đoạn II: Tuyến sinh dục bắt đầu phát triển, kích thước lớn hơn giai đoạn 1 . Đực cái được phân biệt bằng các tế bào trứng và tinh trùng trong tuyến sinh dục. Tuy nhiên, các tế bào trứng còn chưa phát triển, màng nhân rất rõ (hình 3).

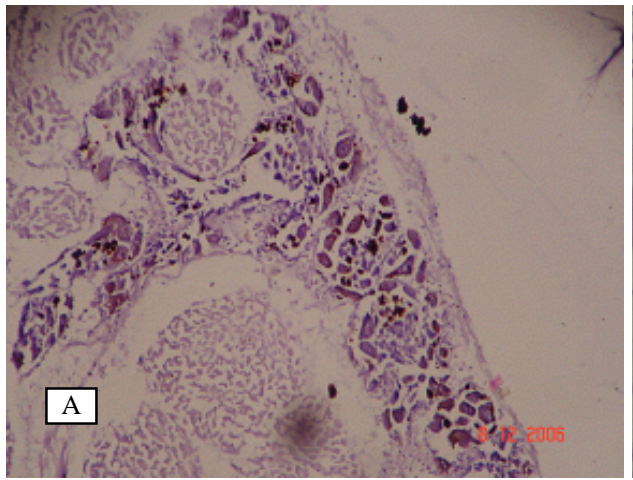

Hình 3. Trứng $(\mathrm{A})$ và tinh sào $(\mathrm{B})$ móng tay giai đoạn $\mathrm{II}$
Giai đoạn III: Là giai đoan thành thục, tuyến sinh dục căng phồng. Tế bào trứng to tròn, nhân tiêu biến. Tinh trùng tập trung thành từng búi (hình 4 ).
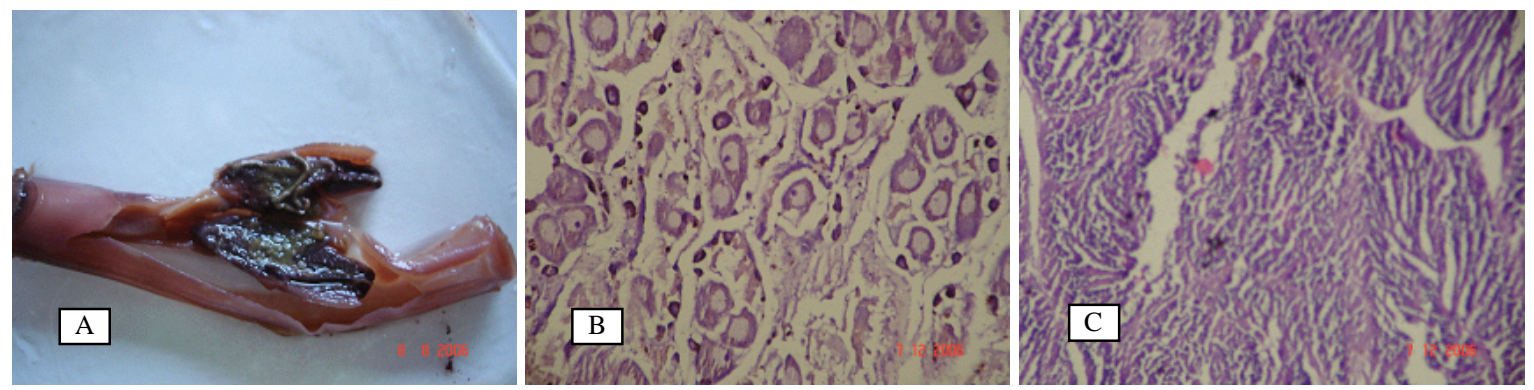

Hình 4. Buồng trứng $(\mathrm{A})$, trứng $(\mathrm{B})$ và tinh sào $(\mathrm{C})$ móng tay giai đoạn $\mathrm{III}$

Giai đoạn IV: Là giai đoạn đẻ xong, buồng trứng xẹp, mềm, trong buồng trứng còn rải rác 1 số trứng giai đoạn III. Sau giai đoạn này, tuyến sinh dục chuyển sang giai đoạn I (hình 5).
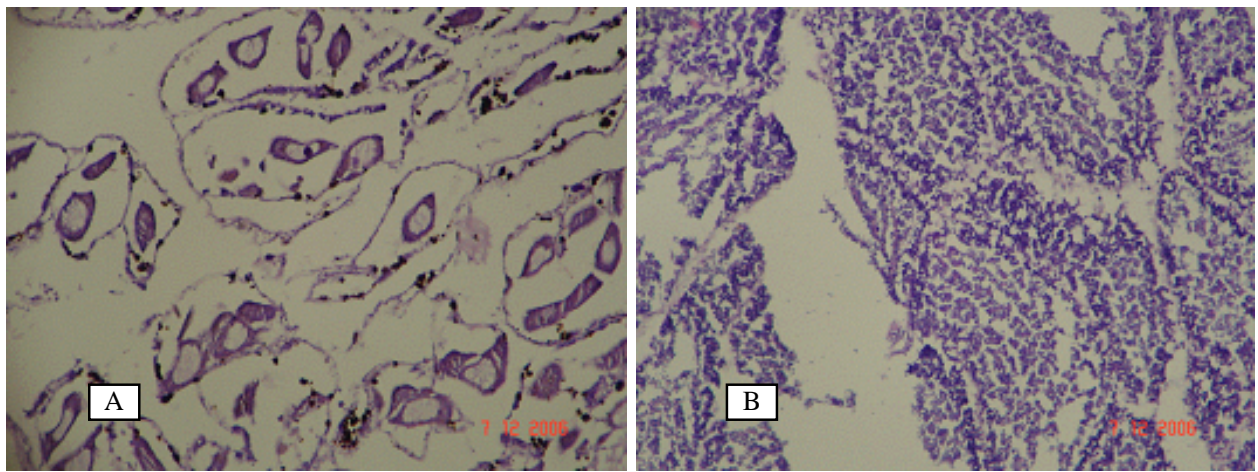

Hình 5. Trứng $(\mathrm{A})$ và tinh sào $(\mathrm{B})$ móng tay giai đoạn $\mathrm{IV}$ 


\section{Mùa vụ sinh sản}

Kết quả phân tích các giai đoạn phát triển tuyến sinh dục theo thời gian được trình bày ở hình 6 cho thấy tuyến sinh dục cái giai đoạn II xuất hiện ở hầu hêt các tháng thu mẫu. Xu thế chung có thể nhận thấy là ở tháng 8 bắt đầu có cá thể cái thành thục sinh dục và đạt đỉnh vào tháng 12 và giảm dần đến tháng $3-4$ năm sau. Vào các tháng 4 - 5 xuất hiện các cá thể cái đã đẻ (tuyến sinh dục ở giai đọan IV). Móng tay có giá trị độ béo tăng dần trong các tháng 7 - 9, hơi giảm trong các tháng $10-1$ và độ béo thấp trong các tháng 2 - 6 năm sau [7]. Từ 2 chuối số liệu trên có thể suy luận rằng trong giai đoạn từ tháng 7 đến tháng 10 , móng tay tích luỹ chất dinh dưỡng chuẩn bị cho quá trình sinh sản. Đến tháng 12 móng tay thành thục sinh dục và tham gia sinh sản cho đến tháng 3 năm sau. Cũng cần lưu ý là móng tay có thể là loài sinh sản quanh năm với sự xuất hiện của các cá thể cái giai đoạn III và IV trong các tháng 7 - 10 và 4 - 6. Cũng có sự giống nhau về mùa vụ sinh sản so với một số loài khác trong khu vực. Mùa vụ sinh sản của các loài trong giống Solen có khác nhau tùy từng loài cu thể. Bốn loài Solen ở vùng nhiệt đới bao gồm Solen strictus, $S$. thailandicus, $S$. corneus và $S$. regularis có hai mùa sinh sản chính trong năm từ tháng $12-4$ và tháng $6-10$ [8]. Loài $S$. regularis và Ensis arcuatus có mùa vụ sinh sản chính từ tháng 12 đến $6[9,10]$; loài Ensis siliqua có một vụ sinh sản nhưng trong thời gian rất ngắn từ tháng 4 5 [11].

Mùa vụ sinh sản của các loài nhuyễn thể có thể khác nhau tùy từng vùng địa lý [10]. Thời gian kéo dài của mùa vụ sinh sản có thể phụ thuộc vào nhiều yếu tố môi trường như thức ăn, nhiệt độ, độ muối và ánh sáng [12].

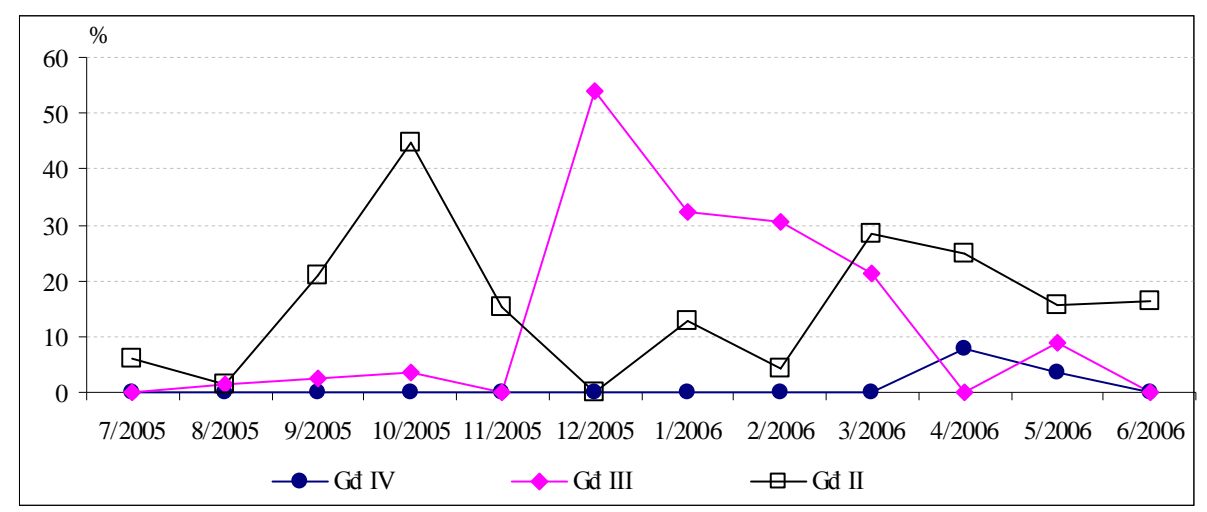

Hình 6. Tỷ lệ phần trăm các giai đoạn phát triển tuyến sinh dục cái của móng tay

\section{Tỷ lệ đực cái}

Kết quả phân tích tuyến sinh dục của móng tay cho thấy, tỷ lệ đực cái của chúng cái xấp xỉ 1:1. Tỷ lệ này tuân theo quy luật giới tính trong tự nhiên. Không phát hiện thấy cá thể lưỡng tính trong mẫu phân tích. Tuy nhiên, số cá thể kích thước nhỏ, chưa xác định được đực cái chiếm $50 \%$ tổng số cá thể phân tích (hình 7 ).

Sự thay đổi tỷ lệ đực cái của móng tay không theo quy luật thời gian. Vào tháng 7 , tháng 9 , tháng 2 và tháng 5 tỷ lệ con cái ít hơn con đực. Vào mùa vụ sinh sản (tháng 12 - 3), biến động tỷ lệ đực cái cũng không theo một quy luật cụ thể. Cá thể có kích thước nhỏ chưa phân biệt đực cái chiếm $50 \%$ tổng số mẫu phân tích.

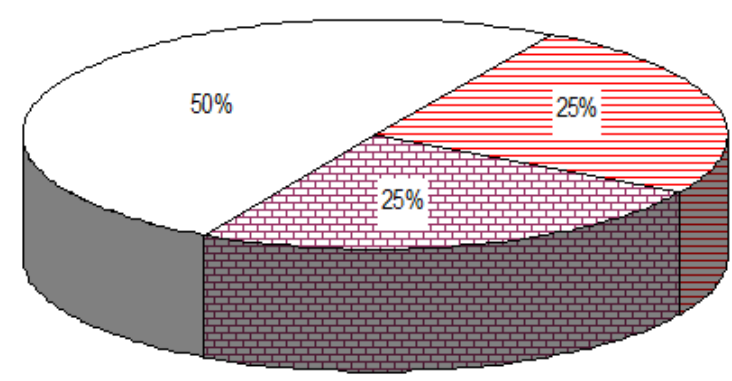

目 Cái 回Đực $\square$ Không xác định

Hình 7. Cấu trúc giới tính của móng tay

Sức sinh sản 
Sức sinh sản của móng tay được đếm và thống kê trên các cá thể cái có tuyến sinh dục ở giai đoạn III. Kết quả thể hiện ở bảng 1 cho thấy sức sinh sản tuyệt đối của móng tay khá cao, sức sinh sản tuyệt đối trung bình là $1.048 .893 \pm 608.964$ trứng/cá thể và sức sinh sản tương đối trung bình là $146.349 \pm$ 95.666 trứng/gam khôi lượng toàn thân. Sức sinh sản cao là một trong những chỉ tiêu đánh giá khả năng bổ sung quần đàn. Đây là loài đẻ trứng, thụ tỉnh ngoài và không chăm sóc con cái. Sức sinh sản lớn sẽ tăng tỷ lệ sống sót bảo vệ sự tồn tại của quần đàn tự nhiên. Điều này cũng phù hợp với tập tính sinh sản và sức sinh sản của nhiều loài hai mảnh vỏ khác $[3,6]$. Mặc khác sức sinh sản cao cũng có thể lý giải một phần biến động số lượng quần đàn của móng tay ở đầm Thủy Triều theo thời gian.

Bảng 1. Sức sinh sản của móng tay ở đầm Thủy Triều

\begin{tabular}{cccc}
\hline Cá thế & $\begin{array}{c}\text { Khối lượng toàn } \\
\text { thân (gam) }\end{array}$ & $\begin{array}{c}\text { Sức sinh sản tuyệt đối } \\
\text { (trứrng/cá thể) }\end{array}$ & $\begin{array}{c}\text { Sức sinh sản tương đối } \\
\text { (trứng/gam khối lượng cơ thể) }\end{array}$ \\
\cline { 2 - 4 } \cline { 3 - 3 } 2 & 2,35 & 705.700 & 300.298 \\
3 & 5,80 & 981.954 & 169.302 \\
4 & 6,35 & 1.105 .924 & 174.161 \\
5 & 6,87 & 938.307 & 136.580 \\
6 & 7,20 & 936.196 & 130.027 \\
7 & 7,50 & 2.312 .964 & 308.395 \\
8 & 7,70 & 2.736 .803 & 355.429 \\
9 & 7,76 & 551.283 & 71.042 \\
10 & 7,86 & 1.171 .380 & 149.031 \\
11 & 8,10 & 806.610 & 99.581 \\
12 & 8,22 & 723.557 & 88.024 \\
13 & 8,73 & 830.306 & 95.110 \\
14 & 9,63 & 909.635 & 94.458 \\
15 & 10,64 & 672.626 & 63.217 \\
16 & 11,63 & 905.873 & 77.891 \\
Trung bình & 16,98 & 493.165 & 29.044 \\
SD & & $\mathbf{1 . 0 4 8 . 8 9 3}$ & $\mathbf{1 4 6 . 3 4 9}$ \\
\hline
\end{tabular}

\section{Kích thước thành thục sinh dục bé nhất}

Kết quả tính toán cho thấy móng tay thành thục lần đầu ở kích thước $69,6 \mathrm{~mm}$ chiều dài (hình 8 , bảng 2).

Kết quả cho thấy kích thước thành thục sinh dục bé nhất của móng tay ở khoảng 70 mm (hình 8 , bảng 2). Như vậy, kích thước khai thác hợp lý đề xuất là $70 \mathrm{~mm}$ trở lên để đảm bảo móng tay có đủ thời gian tham gia sinh sản lần đâu nhằm tái bổ sung nguồn lợi. Theo phân tích đặc điểm sinh trưởng móng tay ở đầm Thủy Triều, ở kích thước $\sim 70 \mathrm{~mm}$ móng tay đạt khoảng 1+ tuổi [7]. Kết quả này cũng tương tự như kết quả nghiên cứu trên các loài hai mảnh vỏ khác như sò huyết ở Trà Vinh [6], tuy nhiên tốc độ này chậm hơn so với Vẹm xanh Perna viridis ở đầm Nha Phu khi Vẹm tham gia sinh sản lần đầu ở nhóm kích thước 21 - 25 mm (2 - 3 tháng tuổi) [13]. Đây là những lợi thế cùng với sức sinh sản cao giúp móng tay nhanh chóng bổ sung quần đàn và cũng là ưu thế làm đối tượng nuôi trồng.

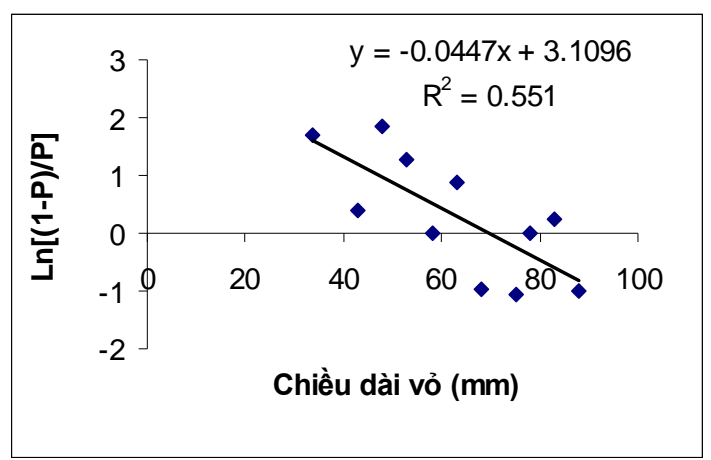

Hình 8. Tương quan giữa chiều dài vỏ và tỷ lệ thành thục của móng tay

Biểu diễn $y=a L+b$, trong đó $y=\operatorname{Ln}[(1-P) / P]$. $P$ : tỷ lẹ thành thuc ở các nhóm kích thuớc khác nhau $(L, m m)$, kích thước thành thuc bé nhất $L_{50}=b / a$ 
Bảng 2. Tính toán kích thước thành thục sinh dục lần đầu của móng tay

\begin{tabular}{cccc}
\hline $\begin{array}{c}\text { Nhóm kích } \\
\text { thước (mm) }\end{array}$ & $\begin{array}{c}\text { Tỷ lệ \% cá thể ở } \\
\text { giai đoạn III }\end{array}$ & $\begin{array}{c}\text { Tỷ lệ \% } \\
\text { quy đồi (P) }\end{array}$ & Ln[(1-P)/P] \\
\hline $36-40$ & 3,23 & 15,4 & 1,7 \\
$41-45$ & 7,41 & 35,35 & 0,4 \\
$46-50$ & 2,86 & 13,64 & 1,85 \\
$51-55$ & 4,55 & 21,69 & 1,28 \\
$56-60$ & 2,86 & 13,64 & 0 \\
$61-65$ & 4,26 & 20,31 & 0,88 \\
$66-70$ & 17,28 & 82,49 & $-0,97$ \\
$71-75$ & 17,48 & 83,41 & $-1,05$ \\
$76-80$ & 20,95 & 100 & 0 \\
$81-85$ & 8,05 & 38,4 & 0,24 \\
$86-90$ & 13,33 & 63,64 & -1 \\
\hline
\end{tabular}

\section{Đề xuất kích thước và mùa vụ khai thác}

Từ các kết quả trên, kích thước khai thác hợp lý được đề xuất là $>70 \mathrm{~mm}$ để đảm bảo cho móng tay có thể tham gia sinh sản lần đầu. Hạn chế khai thác vào mùa vụ sinh sản chính, đặc biệt là từ tháng 12 đến tháng 1 nhằm tạo điều kiện cho móng tay tham gia sinh sản, tái tạo quần đàn. Ngoài ra cần quan tâm đến môi trường sống liên quan để tạo điều kiện cho loài móng tay sinh trưởng, phát triển và tái tạo quần đàn cao nhất, đem lại hiệu quả khai thác và sử dụng nguồn lợi một cách lâu dài. Ngoài ra cần cân nhắc quy hoạch vùng khai thác và vùng hạn chế khai thác dùng làm bãi đẻ cho móng tay và các đối tượng nguồn lợi khác ở đầm Thủy Triều. Để làm điều này cần phối hợp với nhiều nghiên cứu khác để có chiến lược quản lý và quy hoạch hiệu quả.

\section{KẾT LUẬN}

Kết quả bước đầu cho thấy móng tay ở đầm Thuỷ Triều là loài phân tính có tuyển sinh dục phát triển theo 4 giai đoạn với tỷ lệ đực cái xấp xî 1:1. Mùa vư sinh sản của móng tay kéo dài từ tháng 12 đến tháng 3 năm sau, rộ nhất vào tháng 12. Các tính toán cho phép xác định móng tay thành thục sinh dục lần đầu ở kích thước $69,6 \mathrm{~mm}$ chiều dài vỏ. Sức sinh sản tuyệt đối trung bình của móng tay là $1.048 .893 \pm$ 608.964 trứng/cá thể và sức sinh sản tương đối trung bình là $146.349 \pm 95.666$ trứng/gam khối lượng. Nên hạn chế khai thác móng tay vào mùa sinh sản từ tháng 12 đến tháng 1 tạo cơ hội cho móng tay tham gia sinh sản và kích thước khai thác hợp lý của móng tay phải lớn hơn $70 \mathrm{~mm}$ khi móng tay đã tham gia sinh sản lần đầu. Kết quả nghiên cứu đã xác định một số đặc điểm sinh học sinh sản của loài móng tay ở đầm Thủy Triều. Tuy nhiên còn nhiều vấn đề cần nghiên cứu tiếp theo như các yếu tố môi trường liên quan đên mùa vụ sinh sản, các bãi đẻ, môi trường sống con non và con trưởng thành. Các yếu tố này sẽ bổ sung cho kết quả sinh học sinh sản góp phần cung cấp cơ sở khoa học cho việc quản lý khai thác nguồn lợi một cách hiệu quả và bền vững.

Lời cảm ơn: Chúng tôi xin cản ơn tỉnh Khánh Hoà đã tài trợ kinh phí nghiên cứu này. Cảm ơn chị Nguyễn Thị Hòa (Sở Nông nghiệp và Phát triển Nông thôn tỉnh Khánh Hòa) và các chị Lê Thị Diệp Thảo, Lê Bích Thuỷ (Sở Khoa học và Công nghệ tỉnh Khánh Hoà) đã tích cực tạo điều kiện để hoàn thành nghiên cứu. Cảm ơn Huỳnh Minh Sang và Nguyển Thị Kim Bích đã giúp thu và phân tích mấu. Chân thành cảm ơn lãnh đạo và các đồng nghiệp khác tại Viện Hải dương học đã đóng góp ý kiến quý báu để hoàn thành nghiên cứu.

\section{TÀI LIỆ THAM KHẢO}

1. De Villiers, C. J., and Hodgson, A. N., 1993. The filtration and feeding physiology of the infaunal estuarine bivalve Solen cylindraceus Hanley 1843. Journal of Experimental Marine Biology and Ecology, 167(1): 127-142.

2. Hylleberg J., and Kilburn R., 2003. Marine molluscs of Vietnam: annotations, voucher material, and species in need of verification. Phuket Marine Biological Center Special Publication, 28. Phuket Marine Biological Center: Phuket. 300 pp.

3. Baron, J., 1992. Reproductive cycles of the bivalva molluscs Atactodea striata (Gmelin), Gafarium tumidum Roding and Anadara scapha (L.) in New Caledonia. Marine and Freshwater Research, 43(2): 393-401.

4. King, M., 2001. Fisheries biology, Assessment and management. Fishing new book. Blackwell Science Ltd. 341 pp. Wiley.

5. Broom, M. J., 1982. Structure and seasonality in a Malaysian mudflat community. Estuarine, Coastal and Shelf Science, 15(2): 135-150. 
6. Trương Sĩ Kỳ, Đỗ Hũu Hoàng, Hứa Thái Tuyến 1996. Đặc điểm sinh sản của Sò Huyết (Anadara granosa) ở vùng ven biển Trà Vinh, Tuyển Tập Nghiên Cứu Biển, Tập VII, Tr. 103-112.

7. Hứa Thái Tuyến, Đỗ Hũu Hoàng, 2013. Một số đặc điểm sinh truởng của móng tay Solen thachi Cosel, 2002 ở đầm Thủy Triều, Cam Lâm, Khánh Hòa. Tuyển Tập Nghiên Cứu Biển, 19: 159-165.

8. Narong, V., 2007. Don Hoi Lot tidal flats: Sustainable harvesting of razor clams. Paper presented at The Regional Training Course on Sustainable Use and Management of Coastal Wetlands held in Faculty of Environment and Resource Studies, 5-20 November 2007. Mahidol University, Thailand. $7 \mathrm{pp}$.

9. Darriba, S., San Juan, F., and Guerra, A., 2004. Reproductive cycle of the razor clam Ensis arcuatus (Jeffreys, 1865) in northwest Spain and its relation to environmental conditions. Journal of Experimental Marine Biology and Ecology, 311(1): 101-115.
10. Rinyod, A. M. R., and Rahim, S. A. K. A., 2011. Reproductive cycle of the razor clam Solen regularis Dunker, 1862 in the western part of Sarawak, Malaysia, based on gonadal condition index. Journal of Sustainability Science and Management, 6(1): 10-18.

11. Darriba, S., San Juan, F., and Guerra, A., 2005. Gametogenic cycle of Ensis siliqua (Linnaeus, 1758) in the Ría de Corcubión, northwestern Spain. Journal of Molluscan Studies, 71(1): 47-51.

12. Remacha-Triviño, A. I., and Anadon, N., 2006. Reproductive cycle of the razor clam Solen marginatus (Pulteney 1799) in Spain: a comparative study in three different locations. Journal of Shellfish Research, 25(3): 869-876.

13. Hứa Thái Tuyến, Trương Sĩ Kỳ, Nguyễn Thị Kim Bích, Đỗ Hũu Hoàng, 2004. Phát triển tuyến sinh dục và sự bổ sung nguồn giống Vẹm xanh (Perna viridis) ở Nha Phu, Khánh Hoà. Tuyển tập báo cáo Hội nghị Khoa học "Biển Đông, 2002". Nxb. Nông nghiệp. Tr. 189-196.

\title{
REPRODUCTIVE BIOLOGY OF RAZOR CLAM SOLEN THACHI COSEL, 2002 AT THUY TRIEU LAGOON - KHANH HOA
}

\author{
Do Huu Hoang, Hua Thai Tuyen \\ Institute of Oceanography-VAST
}

\begin{abstract}
Razor clam Solen thachi Cosel, 2002 is one of the high valuable species distributed at Thuy Trieu lagoon, Khanh Hoa. The aim of this paper was to examine some reproductive biology characteristics of razor clam. Samples of razor clam were collected monthly with a total of 822 inds. at Thuy Trieu lagoon and analysed at the laboratory of the Institute of Oceanography. Results of analysis showed that sex ratio was about 1:1. Spawning season was mainly between December and March of the following year, with the peak in December. The absolute fecundity was 1,048,893 $\pm 608,964$ eggs per individual, while the relative fecundity was 146,349 \pm 95,666 eggs/gram of body weight. Length of the first maturity was recorded at $69.6 \mathrm{~mm}$ of shell length. This paper provided baseline data for management and sustainable exploitation of marine living resources.
\end{abstract}

Keywords: Razor clam, Solen, reproductive characteristic. 